\title{
A FORMAÇÃO HUMANA EM TEMPOS DE ESCOLA SEM PARTIDO E SEUS REFLEXOS NAS POLÍTICAS EDUCACIONAIS: AS CONCEPÇÕES DA MÍDIA VEICULADAS PELO JORNAL FOLHA DE S. PAULO
}

Renata Peres Barbosa Mariana de Freitas Pereira

\begin{abstract}
RESUMO: A sociedade atual tem demonstrado o avanço de ideias e valores conservadores, debate este que se torna presente no campo educacional em defesa a uma educação "neutra" e "não ideológica". O objetivo do presente artigo é problematizar as concepções de formação presentes no campo das Políticas Educacionais, expresso pelas premissas do movimento Escola Sem Partido, através da construção do discurso midiático, utilizando como fonte os artigos jornalísticos do jornal Folha de S. Paulo. Apresenta-se como como referencial bibliográfico a Teoria Crítica da Sociedade, fundamentada em Theodor W. Adorno, que tem como horizonte uma educação para emancipação capaz de problematizar as condições de dominação e regressão presentes na sociedade atual em um contexto social de intolerância, violência e desigualdade. Quanto ao enfoque metodológico, trata-se de uma pesquisa bibliográfica, documental e hemerográfica.
\end{abstract}

PALAVRAS-CHAVE: Teoria Crítica da Sociedade. Escola sem partido. Folha de S. Paulo.

\section{INTRODUÇão}

Em novembro de 2019, um deputado do PSL - Partido Social Liberal, registra uma denúncia contra uma escola estadual do estado Paraná por permitir a apresentação de uma peça de teatro ${ }^{1}$, sob alegação de que a peça promove "doutrinação política". A denúncia foi entregue à Ministra dos Direitos Humanos, Damares Alves, que anuncia a pretensão de criar um canal para denunciar professores "contrários à família" (REVISTA FÓRUM, 2019).

O exemplo da censura à peça de teatro serve de apoio para ilustrar os avanços de ideias e valores conservadores na sociedade atual. Discussões em torno desses ideais têm se adentrado no campo educacional com um crescente debate em defesa a uma educação "neutra" e "não ideológica", levantando uma forte crítica aos professores e professoras tidos como "doutrinadores" e "inimigos da família", que reflete na elaboração das políticas públicas educacionais.

Sob o slogan "diga não a doutrinação", as pautas da chamada onda conservadora vêm crescendo e ganhando legitimidade, podendo ser observadas pelas defesas do movimento Escola Sem Partido, que incide em propostas pedagógicas e nas políticas educacionais, parte de uma agenda mais ampla (MIGUEL, 2016). Observa-se a pretensão que tais pautas sejam amparadas pelo aparato legal, já presente em diversos debates nas casas legislativas por todo o Brasil, a saber: os inúmeros projetos de Lei que tramitaram em território nacional contra a "doutrinação dos professores", que previa a própria alteração da Lei de Diretrizes e Bases da Educação Nacional com a inclusão e ênfase do princípio da "neutralidade política, ideológica e religiosa"; a exclusão das discussões de gênero no documento da Base Nacional Comum Curricular e em diversos planos estaduais e municipais de educação, entre outros. (PENNA, 2017; FERREIRA, 2015; MIGUEL, 2016; ROSENO, 2017).

A proposta de educação subjacente a tais discursos tem sido recorrente na mídia, produzindo consenso e colocado na mira professores e escolas em um clima de denuncismo, hostilização

1 A peça chamada "Quando Quebra Queima", que aborda as ocupações de escolas do Paraná do ano de 2016 - compõe a Mostra Nacional de Artes Cênicas de 2019, vinculada ao FILO - Festival Internacional de Londrina, festival realizado a mais de cinquenta anos e reconhecido internacionalmente. Mais informações sobre a peça: https://filo.art.br/espetaculos/quando-quebra-queima/ 
e censura. Face às questões levantadas, buscamos uma resposta teórica no quadro conceitual da Teoria Crítica da Sociedade, mais especificamente, em Theodor Adorno, a partir de sua máxima educativa de que "Auschwitz não se repita" (ADORNO, 1995, p.119).

Auschwitz representa o limite da experiência empobrecida, e revela o potencial regressivo das relações sociais que se sustentam pela intolerância, pelo ódio e pelo extermínio que, sob a égide da razão instrumental, é capaz de produzir a barbárie pelo crivo da semiformação (ADORNO, 2010). Para o filósofo, o genocídio planejado representou uma regressão da humanidade e o mais atormentador é que as condições que geraram a barbárie permanecem na sociedade. Dessa forma, é necessário buscar o esclarecimento geral e a emancipação dos indivíduos.

Além disso, localizamos em diversas pesquisas recentes evidências da aproximação entre o discurso de cunho autoritário com os interesses de mercado, dito de outro modo, pesquisas que revelam o alinhamento das pautas dos reformadores educacionais com o neoconservadorismo (FREITAS, 2012; FRIGOTTO, 2017; PERONI ET AL, 2017). Nesse sentido, concordamos que o movimento escola sem partido é o "arquétipo da semiformação" (BARBOSA; SILVA, 2019).

Este artigo tem por objetivo problematizar a concepção de formação humana em tempos Escola Sem Partido e sua presença nas políticas educacionais atuais, a partir do discurso midiático. Para isso, no primeiro momento, apresenta-se um breve histórico e principais pautas do movimento Escola Sem Partido, evidenciando sua relação com um cenário mais amplo de avanço das políticas conservadoras e sua relação com as políticas públicas. Em seguida, apresenta-se os resultados da pesquisa hemerográfica, realizada em artigos sobre o tema do Escola sem Partido publicadas no jornal Folha de São Paulo no ano de 2018, que evidenciam o debate pela via midiática. E, por fim, realizamos uma análise do discurso midiático à luz do referencial de análise da Teoria Crítica da Sociedade.

Utilizou-se como estratégia metodológica a pesquisa bibliográfica, documental e hemerográfica, e insere-se numa abordagem qualitativa. A pesquisa foi desenvolvida a partir das matérias publicadas no jornal Folha de São Paulo, no ano de 2018, sobre o tema do Escola sem Partido, num total de 29 matérias, analisadas por meio da literatura.

\section{Sobre Escola Sem Partido: breve histórico e principais pautas}

Em setembro de 2003, um pai indignado com o professor de história da escola de sua filha, escreveu uma carta aberta ao docente por conta de uma analogia feita em sua aula entre Che Guevara $^{2}$ e São Francisco de Assis $^{3}$, ao citar que ambos abriam mão de tudo por conta de uma ideologia. Miguel Nagib, o pai e idealizador da proposta, afirmou que "As pessoas que querem fazer a cabeça das crianças associam as duas coisas e acabam dizendo que Che Guevara é um santo" (BEDINELLI, 2016). Tal episódio, em 2004, motiva Nagib a lutar pelo suposto "abuso" que, segundo ele, as crianças estão sofrendo nas escolas, com a criação do Movimento Escola sem Partido (ESP).

Nota-se que desde 2014 o movimento tem adquirido notoriedade no debate público e suas pautas influenciado o campo das políticas públicas. Em 2014, o estado e município do Rio de Janeiro foram os pioneiros em apresentar projeto de lei (PL) com as pautas do movimento. O então deputado estadual do Rio de Janeiro, Flávio Bolsonaro, solicitou a Nagib que elaborasse um projeto com base em suas propostas, sendo assim criado o Projeto de Lei n 2974/2014.

$2{ }^{2}$ Quem foi: revolucionário marxista, médico, autor, guerrilheiro, diplomata e teórico militar argentino.

$3{ }^{3}$ Quem foi: frade católico da Itália. 
Analogamente, o vereador do município do RJ, Carlos Bolsonaro não demorou muito e, com poucas adaptações ao projeto original, apresentou o PL 867/2014 (PENNA, 2016, p.44). Já no ano seguinte, em 2015, passa a tramitar na esfera nacional pelo PL 867/2015, de autoria do Deputado Federal Izalci Lucas. Vale destacar que, a partir de então o movimento passa a ganhar visibilidade na mídia por conta de sua tramitação nas esferas legislativas em todo o país.

No site do ESP foram disponibilizados anteprojetos de lei, que servem como modelos para que vereadores e deputados apresentem em seus estados e municípios. Desse modo, as casas legislativas seguem como propostas muito semelhantes, quando não idênticas. Os projetos de lei normalmente iniciam apresentando os princípios que devem orientar o sistema de ensino, já anunciando uma pretensão de tal concepção adentrar o aparato legal educacional. $O$ trecho a seguir é da autoria do Deputado Federal Izalci Lucas na proposta de integrar tais princípio à Lei de Diretrizes e Bases da Educação Nacional, pelo PL 867/2015, e são eles:

Art. $2^{\circ}$. A educação nacional atenderá aos seguintes princípios:

I - neutralidade política, ideológica e religiosa do Estado;

II - pluralismo de ideias no ambiente acadêmico;

III - liberdade de aprender, como projeção específica, no campo da educação, da liberdade de consciência;

IV - liberdade de crença;

$\mathrm{V}$ - reconhecimento da vulnerabilidade do educando como parte mais fraca na relação de aprendizado;

VI - educação e informação do estudante quanto aos direitos compreendidos em sua liberdade de consciência e de crença;

VII - direito dos pais a que seus filhos recebam a educação moral que esteja de acordo com suas próprias convicções. (PL 867/2015, grifo nosso)

Uma das principais pautas do movimento é o combate "doutrinação política e ideológica" e a busca pela neutralidade de conteúdos tidos como "ideológicos", censura essa pode ser sobre aulas com temas relacionados a cotidiano escolar e práticas sociais, sendo permitidos apenas conhecimentos livres de qualquer viés ideológico. Nesse sentido, o professor, sendo autoridade máxima na sala de aula, se aproveita da "audiência cativa" dos alunos para "fazer a cabeça" dos estudantes. Observa-se que há uma construção caricata da figura do professor como "doutrinador" que 4tenta atrair os estudantes, "um 'abusador', um 'parasita ideológico', um 'sequestrador', como algo que 'deva ser combatido"” (BARBOSA, 2019, p. 175). Na página há um incentivo que os alunos filmem educadores que não cumpram esses "deveres" e os denunciem ao Movimento Escola Sem Partido.

Segundo o site do Escola Sem Partido é necessário que ocorra uma "descontaminação e desmopolização política e ideológica nas escolas" (NAGIB, 2018), relacionado com a ideia de que existe uma conspiração da esquerda (PENNA, 2017). Ou seja, o movimento cria uma visão estereotipada e hostil do espaço onde se é produzido o conhecimento.

Além disso, ao apresentar os "deveres do professor" o movimento busca assegurar que a educação moral dada aos alunos esteja de acordo com a convicção familiar, ferindo o direito do cidadão do pleno desenvolvimento sem quaisquer discriminações.

4 Disponível em: https://www.escolasempartido.org/. Acesso em: 12 de agosto de 2018. 


\section{Discursos da mídia: A PESQUisa HEMEROGRÁfica}

Neste tópico apresenta-se as perspectivas levantadas sobre o movimento Escola Sem Partido construídas pelo discurso midiático. A pesquisa se debruçou sobre os artigos que foram publicados pelo veículo de comunicação Folha de S. Paulo sobre o movimento Escola Sem Partido, desta forma trata-se de uma pesquisa hemerográfica - uma pesquisa a partir de artigos jornalísticos. Foi realizado um levantamento de todos os artigos publicados sobre o movimento Escola Sem Partido durante o ano de 2018, visto que a temática que alcançou grande repercussão na mídia do país.

A busca de material foi realizada na edição online do jornal Folha de S. Paulo (folha.com). $\mathrm{Na}$ opção busca avançada, disponível na página da web, foi possível selecionar o texto exato, "Escola Sem Partido", assim como a data exata, entre o dia 1 de janeiro a 31 de dezembro de 2018. Da palavra chave no tempo determinado encontramos 29 reportagens.

As reportagens foram organizadas por ordem cronológica, identificando cada uma delas: título, autor, vínculo do autor (colunista, professor, leitor, etc;) e os Cadernos em que foram publicadas (Primeiro Caderno, Cotidiano e Esporte, Cotidiano e Esporte - Educação Nacional-, Ilustrada, Ilustríssima e Painel do Leitor). A partir da coleta de dados foi possível mapear e classificar as reportagens e realizar uma análise das matérias, quem eram atores sociais e os temas em debate. As 29 reportagens estavam dispostas em 7 diferentes cadernos do jornal. Quanto aos atores sociais citados nas matérias jornalísticas destacamos a diversidade de setores sociais, como pessoas, órgãos públicos e documentos normativos.

\section{Discursos da Mídia: TEMAS EM DEBATE}

O tema Escola Sem Partido foi levantado nas mais variadas discussões e debates. Observamos uma sequência de reportagens que tratavam da tramitação nas esferas legais de poder sobre o Projeto de Lei Escola Sem Partido que, no ano de 2018, teve muito destaque por conta das eleições presidenciais. Outros temas encontrados foram a respeito do avanço do conservadorismo na sociedade e a intolerância com relação às minorias.

A defesa ao ensino a distância também apareceu como uma demanda do movimento Escola Sem Partido como forma de combater o "marxismo e evitar que a ideologia de gênero" se dissemine nas escolas. Além da crítica a instituição escolar, também foi possível perceber uma crítica direta aos professores e acusações como doutrinadores.

Vale destacar a grande evidência do posicionamento da família Bolsonaro, que apareceu como elemento ativo na discussão pelo pioneirismo nos Projeto de Lei Escola Sem Partido e eleições. Flávio Bolsonaro foi um agente ativo para a formulação do projeto de lei no Rio de Janeiro e seu nome aparecia quando a temática era da tramitação nas casas legislativas. Candidato à presidência de 2018, Jair Bolsonaro, fez uso da sua voz para propagar o documento e se posicionar contra a doutrinação e ideologia de gênero nas escolas, defendeu o ensino a distância para evitar influências marxistas no ensino e ainda apresentou sua intenção de retirar as contribuições de Paulo Freire, um grande pensador da educação, do Ministério da Educação para combater o pensamento crítico.

Podemos observar que uma das reportagens faz menção ao órgão federal sobre a averiguação de uma disciplina proposta pela UNB que se chamava "O golpe de 2016 e o futuro da democracia no Brasil”. A argumentação do Ministro da Educação era de que a disciplina não 
era configurada como ciência e que tinha a intenção de promover a tese de um partido político. Essa notícia nos atenta sobre a intolerância que tem se adentrado nas Universidades por conta de divergências políticas.

Trouxe também um panorama de como o projeto de lei Escola Sem Partido tem avançado na câmara de deputados. As reportagens relacionavam o avanço das propostas com proibições e limites colocados pelo documento, como por exemplo o uso de das palavras "gênero" ou "orientação sexual". Os autores ainda deixavam claro que os responsáveis pela tramitação "favorável" ao movimento eram de responsabilidade da bancada evangélica por resguardar princípios conservadores ao combater a doutrinação ideológica.

Entidades, como a Curadoria Geral da República e o Ministério Público, julgaram o Projeto de Lei Escola Sem Partido inconstitucional por não favorecer a liberdade de ensinar e aprender. Enquanto o Ministério da Educação, desqualifica o ensino democrático e de justiça social. Destacamos a referência feita à Lei de Diretrizes e Bases da Educação Nacional, a qual o entrevistado defende um ponto de vista pedagógico da escola plural.

As temáticas eram sobre representatividade das minorias, focalizando a discussão em homossexuais, mulheres e afrodescendentes. Um artigo jornalístico nos fez refletir sobre uma música, "Exu nas escolas", que representa a defesa ao ensino da cultura afro-brasileira nas salas de aula.

\section{Argumentos favoráveis e contrários}

A partir da análise das temáticas, foi possível separar as reportagens em categorias de posicionamento "favorável ou contrário" a fim de encontrar perspectivas em comum sobre o Movimento Escola Sem Partido. Foram contabilizados 18 artigos em que o posicionamento foi contrário ao movimento escola sem partido e os favoráveis somaram um total de 9.

Os argumentos trazidos pelos contrários ao Movimento Escola Sem Partido eram em defesa de uma escola plural, da liberdade de ensinar e aprender e da importância de uma educação política. Além disso, de modo geral, o movimento foi classificado como inconstitucional, conservador e regressivo.

Argumentos sobre a nova cultura política brasileira tiveram destaque entre as matérias, evidenciado pela crescente onda de conservadorismo na sociedade atual. De acordo com os argumentos, trata-se de uma nova maneira de fazer política, que se mostra reacionária, autoritária e regressiva, como a partir de, por exemplo, proibições das discussões de gênero e orientação sexual nas escolas; ou ainda, exposições em museus sendo canceladas; o potencial catastrófico das eleições de outubro.

Sobre o Projeto de Lei, as matérias levantam críticas sobre a inconstitucionalidade e proibições de conteúdos e termos no documento. Segundo os reportagens, esses pontos inviabilizam e desconsideram outros direitos garantidos na Constituição de 1998 e também na Lei de Diretrizes e Bases da Educação - LDB 1996, que tem princípios pautados na liberdade de educar e aprender.

Por outro lado, as reportagens elencadas como favoráveis ao Movimento Escola Sem Partido, os principais temas foram o papel dos professores, a defesa da educação a distância, a defesa da neutralidade do conhecimento, o combate a doutrinação e ideologia de gênero. Foi possível perceber a consonância dos argumentos favoráveis com os pressupostos do movimento ESP. 
Destaca-se que um principal argumento trazido pelas matérias favoráveis ao Movimento Escola Sem Partido é o ataque e a crítica a figura do professor. Começando com um diagnóstico da prática docente frente à precarização da educação e suposição de que os professores não formulam suas próprias ideias, e sim se reproduzem ideais da esquerda.

É apresentado argumentos a fim de controlar a ação docente com a censura de conteúdos de formação política e proibições quanto aos estudos de gênero e questões raciais. Frente a esse cenário, uma forma de conter e controlar os educadores seria a proposta de educação à distância, nos níveis fundamental e superior. Segundo as matérias, essa seria uma forma de garantir a liberdade da família e controlar a doutrinação.

\section{Sobre o ALINHAMENTO ENTRE OS INTERESSES DE MERCADO, E O DisCURSO NEOCONSERVADOR E A CRISE DA FORMAÇÃO CULTURAL}

A partir da Teoria Crítica da Sociedade, mais especificamente em Theodor Adorno, entende-se que os processos formativos não são processos desconectados da realidade social, política e cultural. Nesse sentido, compreende-se que as concepções que embasam o Movimento Escola Sem Partido são reflexos de uma determinada sociedade ancorada por concepções de caráter técnico e utilitarista. $\mathrm{Na}$ análise das matérias, destaca-se o caráter pragmático das pautas do ESP que se desdobra em dois aspectos: um primeiro aspecto, sobre o alinhamento entre os interesses de mercado e o discurso neoconservador; e, um segundo aspecto, sobre a relação entre a pauta da batalha cultural e ideológica como expressão da crise da formação cultural, expresso por práticas de censura, perseguição, intolerância. Neste tópico, realiza-se uma análise de tais aspectos localizados na intersecção das matérias, das pautas do ESP e de uma agenda social mais ampla.

Nos escritos frankfurtianos encontra-se subsídios para pensar os problemas sociais contemporâneos, entre eles a formação cultural, em que a educação escolar tem importante papel. Na obra Educação e Emancipação (1995) destaca-se a função do refletir, a importância da escola no processo de desbarbarização e a assimilação do passado como forma de esclarecimento.

No ensaio Teoria da Semiformação (2010), Adorno tece considerações sobre uma razão despojada de seu potencial crítico e que tem como resultado a atrofia da capacidade de reflexão, de primazia de um progresso técnico que não está a serviço do progresso humanitário. A semiformação trata-se do "espírito dominado pelo fetiche da mercadoria", de uma produtividade que leva a destruição, de uma eficiência irracional, com déficit ético, a serviço da barbárie. Trata-se de uma sociedade administrada, que cria formas de vida que rejeitam as perspectivas históricas de liberdade, e que nega os pressupostos de uma formação para a emancipação, para a experiência. Contrapõe-se, desse modo, ao pensamento pragmático, da lógica identitária e mecanicista, que se esquece de seus fins e produz barbárie. A Teoria Crítica, nesse sentido, resiste aos irracionalismos que levam a barbárie, resiste a semiformação produzida na lógica do capital, da mercadoria, do lucro, da ciência enquanto força produtivo submetida aos ditames do mercado.

As relações sociais não afetam somente as condições da produção econômica e material, mas também interagem no plano da "subjetividade", onde originam relações de dominação. Ao lado da identificação entre ciência e forças produtivas, já assinalada, a integração social das classes trabalhadoras, a manipulação das massas no nazifascismo e a expansão das sociedades consumistas seriam exemplos concretos dessas formas de dominação (ADORNO, 1996, p. 19). 
Diversas pesquisas, como Frigotto (2017), Freitas (2012) e Peroni, Caetano e Lima (2017), situam que o movimento ESP constitui-se alinhado a interesses neoliberais e conservadores, que direcionam as políticas educacionais orientadas por princípio mercantis pela via do interesse privado, da moralidade e da tradição.

As pautas do movimento, mesmo as que se originam a partir de ideais neoliberais, assumem um caráter bastante neoconservador, especialmente no que diz respeito à regulamentação do trabalho dos professores, que se torna padronizado e policiado, não somente em relação ao conteúdo a ser apresentado, mas também em relação aos métodos (PERONI, CAETANO E LIMA, 2017, p 423).

O movimento ESP tem se mostrado como um elemento ativo na negociação das políticas educacionais, como exemplo recente, na elaboração da Base Nacional Comum Curricular (BNCC), documento que define o conjunto de aprendizagem essenciais ao longo da educação básica. Nesse sentido, o ESP, vem protagonizando discussões sobre o que deve ser ensinado nas escolas e o que deve ser excluído, no âmbito das políticas públicas. Peroni, Caetano e Lima (2017) evidenciam as aproximações da relação entre o público e o privado no financiamento do movimento ESP com o movimento pela Base Nacional Comum Curricular e a relação de desvelar os reais interesses e os impactos no campo educativo:

O movimento Escola sem Partido (ESP) tem-se mostrado um sujeito coletivo atuante nas negociações políticas sobre a elaboração da Base Nacional Curricular Comum (BNCC) representado por parlamentares apoiadores e outros entusiastas, que participam ativamente do debate público acerca do documento, especialmente a partir da divulgação e sua segunda versão, em 2016. (PERONI, CAETANO E LIMA, 2017, p. 422).

Em uma das reportagens analisadas, Jair Bolsonaro defende o ensino a distância como estratégia para combater o marxismo. O posicionamento de Jair Bolsonaro também nos permite aproximar com as pesquisas que evidenciam essa aproximação entre os interesses do movimento com os interesses de mercado na tentativa de privatização da educação pública. Segundo Frigotto (2017) o movimento Escola Sem Partido possui um partido, o partido do que o desejável ao mercado que transforma os processos formativos em mercadoria: "a escola do partido absoluto e único [...] um partido que ameaça os fundamentos da liberdade e da democracia" (p. 31).

Adorno (1995) afirma que existe uma pressão maior que supera toda a educação, uma organização ideológica baseada na estrutura social do trabalho e no capitalismo. A formação cultural, ao distanciar-se de sua função real, tornou-se falsa visto que a sociedade valoriza os modos de produção técnicos e utilitaristas, submetendo-se à adaptação e a lógica da mercadoria. Esse exercício de simplificar os processos de formação é reduzido e regressivo, favorecendo e intensificando os meios de adaptação.

Por inúmeros canais, fornecem-se as massas bens de formação cultural. Neutralizados e petrificados, no entanto, ajudam a manter no seu devido lugar aquelas para os quais nada existe de muito elevado ou caro. Isso se consegue ao ajustar-se o conteúdo da formação, pelos mecanismos do mercado, a consciência dos que foram excluídos do privilégio da cultural (ADORNO, 2010, p.16).

O contexto da sociedade atual pode ser ilustrado pela palavra obscurantismos, que significa escuridão e privação de luz, falta de instrução e ignorância. Segundo Adorno (2010) a consequência uma experiência formativa voltada para instrumentalidade é "confusão e obscu- 
rantismo". Essa é a perspectiva das reportagens "Sol de Maio" e "O mês que não terminou" ao apresentar a tensão política que foi estabelecida no mês de maio por conta da tramitação do Projeto de Lei Escola Sem Partido e suas proibições. Mas não apenas isso, os autores mencionam as exposições em museus canceladas, o potencial catastrófico das eleições presidenciais, o sistema político apodrecido e indícios de perseguição.

A concepção neutra e técnica proposta pelo movimento não condiz com os princípios educativos emancipatórios, são princípios que esvaziam o sentido da formação (ADORNO, 2010). O filósofo sustenta a ideia de uma formação com pressupostos, ou seja, uma formação que dialogue com a realidade social. Dessa forma, defende que processos educativos devem ter uma abordagem política e cultural que busque sensibilizar as pessoas e impedir que atos extremistas, como intolerância, violência, autoritarismo e perseguição, ocorram novamente. Essa seria a importância, como orienta Adorno (1995), de elaborar o passado e criticar o presente em um movimento de evitar a barbárie.

Segundo Adorno (2010) a semiformação é resultado de dois fatores, sendo eles: produção simbólica, a qual há predomínio da instrumentalidade voltada para o conformismo conforme a lógica mercantil, e a identificação com o modelo hegemônico. Portanto, a cultura no capitalismo tornou-se um objeto de consumo e essa condição trouxe consigo uma falta de liberdade e consequentemente a pobreza de espírito.

Nesse cenário, os potenciais formativos são reduzidos e direcionados a um único sentido. Estabelece-se então um modo de pensar conformado, há uma incapacidade de imaginar o mundo e as relações que por ele perpassam de uma forma diferente da qual é. Adorno (1995) compreende e denomina esse modo de pensar de "consciência coisificada".

A questão é que, ao proibir que determinados assuntos sejam tratados nas instituições educativas, nega-se o debate de questões alarmantes da realidade social, suas contradições, ou seja, nega-se a possibilidade de pensar sobre os processos ideológicos que sustentam exclusão, a dominação e a barbárie (BARBOSA, 2019, p. 174-175)

A partir dos artigos jornalísticos "Na câmara, Escola Sem Partido avança, o texto proíbe o termo gênero" e "Marcha Obscurantista" observamos um discurso de caráter autoritário de Flávio Bolsonaro. O redator do documento defende que os alunos devem receber uma educação moral de acordo com o que seus pais priorizam cerceando a liberdade de ensinar dos professores, vetando qualquer ideologia de gênero assim como os termos "gênero" e "educação sexual". A reportagem "Intolerância chega à universidade com bomba, ameaça, e briga judicial" ao narrar conflitos que ocorreram no campus na universidade por conta de intolerância política e de oposição de ideias, traz um reflexo de uma formação limitada e sem sentido.

Sobre a defesa da neutralidade política e ideológica, constitui-se completamente contrária aos princípios democráticos e emancipatórios da formação escolar, simplifica e fragiliza o debate. A defesa da neutralidade científica e política nega a própria natureza dos processos educativos, de modo que a pauta da batalha cultural e ideológica travada no cenário político atual se trata de uma "racionalidade que se sustentam em bases operacionais, de caráter pragmático e autoritário" (BARBOSA, 2019, p. 172).

Segundo Penna (2016) as limitações do movimento impedem a construção de valores para uma conivência democrática e o combate aos valores preconceituosos que estão presentes na sociedade atual. Dessa forma, "Impedir a problematização e a pluralidade de representações 
segundo as quais os alunos estão sendo socializados é reforçar as representações únicas, necessariamente excludentes e que reforçam a desigualdade existente na sociedade" (PENNA. 2016, p.48).

A partir de algumas premissas frankfurtianas, podemos depreender que o movimento Escola Sem Partido incide no papel da educação e nos sentidos de formação, se configurando como uma proposta de educação regressiva, e sua adesão intensa revela o avanço de ideias e valores conservadores na sociedade atual. Para Adorno (1995) o mais importante seria fortalecer a resistência por meio do esclarecimento e "[...] o centro de toda educação política deveria ser que Auschwitz não se repita." (ADORNO, 1995, p.137).

Para Adorno (1995) é de extrema importância conscientizar os indivíduos com a finalidade de se livrar da consciência obscurecida, que os torna incapazes de perceber que as raízes do genocídio, entendendo como uma tendência social, planejada e não acidental, um perigo objetivo, de modo que "a desbarbarização tornou-se a questão mais urgente da educação hoje em dia" (ADORNO, 1995, p. 132).

Concordamos com Maar (1995) que

É preciso romper com a educação enquanto mera apropriação de instrumentos técnicos e receituário para a eficiência, insistindo no aprendizado aberto a elaboração da história e ao contato com o outro não-idêntico, o diferenciado (MAAR, 1995, p.27).

O jornal Folha de S. Paulo se coloca como um elemento ativo nesse sobre a construção do debate acerca do Movimento Escola Sem Partido. Por mais que ainda tenha predominado mais reportagens contrárias ao MESP, o que se destaca é a forte presença do debate no Jornal, e em Cadernos não diretamente ligados à Educação. Ou seja, infere-se que o consenso de que se trata de uma temática importante a ser debatida está sendo construído. Desse modo, ainda que prevaleça argumentos contrários, é uma temática que está em evidência, o que justifica seu estudo.

\section{CONSIDERAÇÕES FINAIS}

O propósito deste artigo, partindo de um referencial bibliográfico sobre a Teoria Crítica da Sociedade, foi de problematizar as concepções de formação presentes no campo das políticas educacionais, expressa pelas pautas do movimento Escola Sem Partido, tendo como fontes os artigos jornalísticos do Folha de S. Paulo.

Os filósofos frunkfurtianos, em seu contexto, vivenciaram e tematizaram os males potencializados pelo nazismo, para exemplificar o resultado da semiformação. $\mathrm{Na}$ sociedade atual podemos perceber que, a partir do conservadorismo, discursos de ódio, intolerância, perseguição e preconceito são potencializados pelos pressupostos defendidos do movimento Escola Sem Partido.

As reflexões sobre a realidade educativa trazida por Theodor W. Adorno nos mostram uma grande exigência de uma educação voltada para a crítica e a autorreflexão como forma de superar a formação regressiva, buscando o esclarecimento e a emancipação. Entendemos que não há educação sem pressupostos, e são exatamente os pressupostos políticos, sociais e culturais que o movimento Escola Sem Partido pretende retirar da formação escolar. A proposta de neutralidade educacional, censura de conteúdos que estejam relacionados a realidade social e posicionar o professor como "doutrinador" contribuem para a hegemonia da semiformação, ressaltando o "ser igual" e "pensar igual", que exclui o diferente, reforçando a intolerância, o 
preconceito e, consequente manutenção das relações de desigualdades. como uma ameaça aos princípios formativos, à liberdade e a democracia.

As pautas do movimento Escola Sem Partido seguem na direção de uma perspectiva de educação regressiva. Esses elementos negados pelo movimento são elementos importantes para a compreensão da formação social e ao negar isso, nega-se a própria formação. A partir do mapeamento dos artigos jornalísticos do Folha de S. Paulo foi possível levantar considerações acerca das perspectivas e discursos de diferentes atores sociais. Constatamos que o Movimento Escola Sem Partido, a partir da grande repercussão na mídia, é um debate que está em construção.

\section{THE HUMAN FORMATION IN ESCOLA SEM PARTIDO TIMES AND THEIR CONSEQUENCES ON EDUCATIONAL POLICIES: THE MEDIA'S CONCEPTS REPORTED BY FOLHA S. PAULO JOURNAL}

ABSTRACT: Current society has shown a big support to conservative ideas and values, this debate has become present in the educational field in defense of a "neutral" and "non-ideological" education. The general objective of this article is to confront the Education concepts figuring on the Educational Policies field, shown by Escola Sem Partido movement' assumptions, through the construction of the media's speech, using as source the newspaper articles of Folha de S. Paulo journal. We present as bibliographical reference the critical theory of society, based on $\mathrm{T}$. W. Adorno, that has the objective of an education for emancipation able to confront the domination and regression conditions present in current society in a social context of intolerance, violence and inequality. Regarding the metodological approach, it is a bibliographic, document and newspaper reasearch.

Keywords: Critical Theory. Escola sem Partido. Folha de S. Paulo.

\section{REFERÊNCIAS}

ADORNO, Theodor W. Educação e Emancipação. Rio de Janeiro: Paz e terra, 1995.

ADORNO, Theodor W. Teoria da Semiformação. Tradução Newton Ramos de Oliveira, Bruno Pucci e Cláudia B. M. de Abreu. In: PUCCI, ZUIN \& LASTÓRIA (orgs). Teoria Crítica e inconformismo: novas perspectivas de pesquisa. Campinas, SP: Autores Associados, 2010, p. 7-40.

BARBOSA, Renata Peres. Escola Sem Partido, balbúrdia ou semiformação generalizada?. In: BELMIRO, Luis; SILVA, Monica Ribeiro. Democracia em ruinas: direitos em riscos. Curitiba: CRV 2019.

BEDINELLI, Talita. O professor da minha filha comparou Che Guevara a São Francisco de Assis. E1 País Brasil, Política. São Paulo, 25 jun. 2016. Disponível em:<http://brasil.elpais.com/brasil/2016/06/23/ politica/1466654550_367696.html>.Acesso em: 28 ago. 2019.

FERREIRA, Windyz Brazão. O conceito de diversidade na BNCC - Relações de poder e interesses ocultos. Revista Retratos da Escola, Brasília, v. 9, n. 17, p. 367-379, jul./dez. 2015. Disponível em: $<$ http//www.esforce.org.br $>367$

FREITAS, Luiz Carlos de. Escolas aprisionadas em uma democracia aprisionada: anotações para uma resistência propositiva. Revista HISTEDBR On-line, Campinas, v. 18, n. 4 [78], p. 906-926, out./dez. 2018.

FREITAS, Luiz Carlos de. Os reformadores empresariais da educação: da desmoralização do magistério à destruição do sistema público de educação. Educação e Sociedade, Campinas, v. 33, n. 119, p. 379-404, 2012.

FRIGOTTO, Gaudêncio. A gênese das teses do Escola sem partido: esfinge e o ovo da serpente que ameaçam a sociedade e a educação. In: FRIGOTTO, Gaudêncio (org.). Escola "sem" partido: esfinge que ameaça a educação e a sociedade brasileira. Rio de Janeiro, UERJ: LPP, 2017.

MAAR, Wolfgang Leo. À guisa da introdução: Adorno e a experiência formativa. In: ADORNO, Theodor W. Educação e Emancipação. Trad. Wolfang Leo Maar. 1. Ed. Rio de Janeiro: Paz e Terra, 1995. p.11-28. 
MIGUEL, Luis Felipe. Da "doutrinação marxista" a "ideologia de gênero" - Escola Sem Partido e as leis da mordaça no parlamento brasileiro. Direito \& Práxis. Rio de Janeiro, v. 07, n. 15, 2016, p. 590-621. NAGIB, Miguel. Quem somos. Escola sem partido - educação sem doutrinação, 2016. Disponível em: $<$ http://www.escolasempartido.org >. Acesso em: 18 out. 2018.

PENNA, Fernando de Araujo. Golpes na história e na escola: o Brasil e a América Latina nos Séculos XX e XXI. In: "Escola Sem Partido" como ameaça a educação democráticas: fabricando o ódio aos professores e destruindo o potencial educacional da escola. Cortez Editora: ANPUH, SP, 2017, p. 247260.

PENNA, Fernando de Araujo. Programa Escola Sem Partido: Uma ameaça à educação emancipatória. In: Narrativas do Rio de Janeiro nas aulas de história. MAUAD Editora LTDA 2016 p.43-58.

PERONI, Vera; CAETANO, Maria; LIMA, Paula. Reformas educacionais hoje: as implicações para a democracia. In: Revista retratos da escola. Brasília, v.11 n.12 p.415-432. 2017.

REVISTA FORUM. Deputado do PSL denuncia escola estadual de Londrina por peça sobre movimento estudantil. [SI], 2019. Disponível em: https://revistaforum.com.br/politica/deputado-do-psl-denunciaescola-estadual-de-londrina-por-peca-sobre-movimento-estudantil/. Acesso em: 23 de nov de 2019.

ROSENO, Camila Dos Passos; SILVA, Janaína Guimarães da Fonseca. Políticas Públicas Educacionais e Gênero e Diversidade Sexual: atos de resistência diante do avanço do conservadorismo do movimento "Escola Sem Partido". Itinerarius Reflectionis, v. 13, n. 2, p. 01-21, 11 ago. 2017. 